\title{
COMPUTER CONTROL OF \\ THE HIGH-VOLTAGE POWER SUPPLY FOR THE ELECTRON CYCLOTRON HEATING SYSTEM
}

by

D.D. CLOW and D.H. KELLMAN 


\section{DISCLAIMER}

This report was prepared as an account of work sponsored by an agency of the United States Government. Neither the United States Government nor any agency thereof, nor any of their employees, makes any warranty, express or implied, or assumes any legal liability or responsibility for the accuracy, completeness, or usefulness of any information, apparatus, product, or process disclosed, or represents that its use would not infringe privately owned rights. Reference herein to any specific commercial product, process, or service by trade name, trademark, manufacturer, or otherwise, does not necessarily constitute or imply its endorsement, recommendation, or favoring by the United States Government or any agency thereof. The views and opinions of authors expressed herein do not necessarily state or reflect those of the United States Government or any agency thereof. 


\title{
COMPUTER CONTROL OF THE HIGH-VOLTAGE POWER SUPPLY FOR THE ELECTRON CYCLOTRON HEATING SYSTEM
}

\author{
by \\ D.D. CLOW' and D.H. KELLMAN
}

This is a preprint of a paper presented at the 14 til IEEE Symposium on Fusion Engineering, September 30-October 3, 1991, San Diego, California, and to be printed in the Proceedings.

\author{
Work supported by \\ U.S. Department of Energy \\ Contract DE-AC03-89ER51114
}

GENERAL ATOMICS PROJECT 3466 OCTOBER 1991
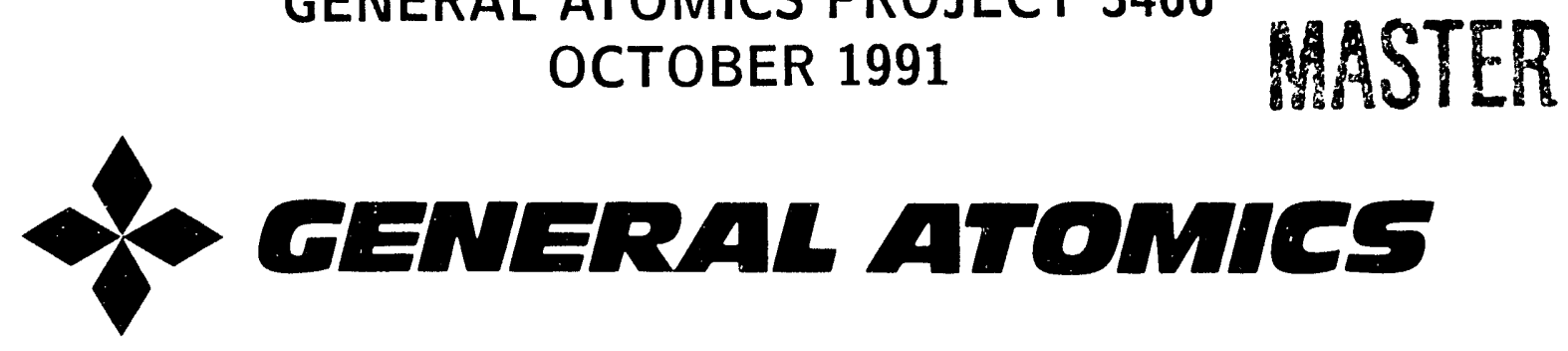


\title{
COMPUTER CONTROL OF THE HIGH-VOLTAGE POWER SUPPLY FOR THE DIII-D ELECTRON CYCLOTRON HEATING SYSTEM
}

\author{
D.D. Clow and D.H. Kellman \\ General Atomics \\ P.O. Box 85608, San Diego, California 92186-9784
}

Abstract: The DIII-D Electron Cyclotron Heating (ECH) high voltage power supply is controlled by a computer. Operational control is input via keyboard and mouse, and computer/ power supply interface is accomplished with a Computer Assisted Monitoring and Control (CAMAC) system. User-friendly tools allow the design and layout of simulated control panels on the computer screen. Panel controls and indicators can be changed, added or deleted, and simple editing of user-specific processes can quickly modify control and fault logic. Databases can be defined, and control panel functions are easily referred to various data channels. User-specific processes are written and linked using Fortran, to manage control and data acquisition through CAMAC. The resulting control system has significant advantages over the hardware it emulates: changes in logic, layout, and function are quickly and easily incorporated; data storage, retrieval, and processing are flexible and simply accomplished; physical components subject to wear and degradation are minimized. In addition, the system can be expanded to multiplex control of several power supplies, each with its own database, through a single computer and console.

\section{Introduction}

The ECH Power Supply (ECH_PS) was originally a Sustaining Neutral Beam Power Supply for the Mirror Fusion Test Facility (MFTF), and was acquired from Lawrence Livermore National Laboratory (LLNL) [1]. Only the high voltage modulator/regulator was installed for Electron Cyclotron Heating (ECH) on the DIII-D tokamak. It is used to supply pulsed high voltage for either the 60 or $110 \mathrm{GHz}$ gyrotrons.

A MicroVax II computer [2] and different controlling software were used instead of the LLNL setup. Most of the effort in making the power supply operational was in the design, development and testing of the controlling software. Figure 1 shows the major components of the controlling hardware and the nine ECH PS subsystems. The controlling software is the main subject of this paper and a broad overview is described herein. Some description of the CAMAC hardware is given for reference.

\section{CAMAC Modules}

The descriptions of the main CAMAC modules/cards referred to in this paper are given in Table I.

\section{The Software}

There are two major components to the ECH_PS software: Vsystem, which is a real-time data acquisition and control package developed by Vista Control Systems [3], and the user specific application software developed for the ECH_PS system and its hardware. The application software runs as detached processes. Vsystem operates on a MicroVax II running VAX/VMS 5.3 and employing DECwindows [4].

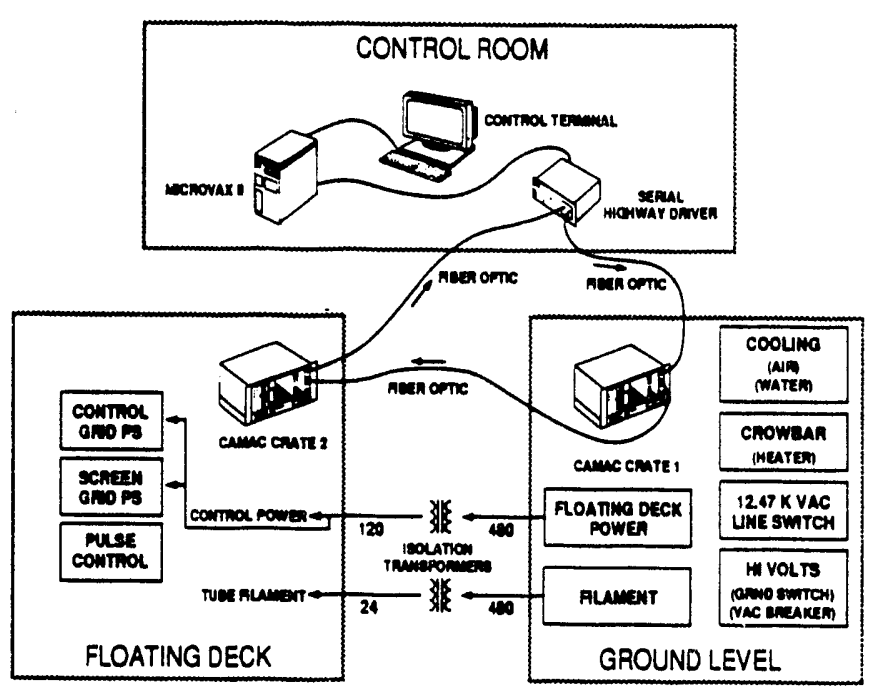

Fig. 1. ECH_PS control system.

Table I: Description of Main CAMAC Modules/Cards

\begin{tabular}{|c|c|c|}
\hline Namie & Description/Function & Location \\
\hline Interlock & $\begin{array}{l}16-1 \text { bit inputs, } 1-8 \text { bit pro- } \\
\text { grammable EPROM outputs. }\end{array}$ & $\begin{array}{l}\text { Ground Level (GL) } \\
\text { Floating Deck (FD) }\end{array}$ \\
\hline AVCA & $\begin{array}{l}\text { Accel Voltage Control } \\
\text { Amplifier. The AVCA is } \\
\text { written to and stores output } \\
\text { parameters such as the } \\
\text { interrupt duration, max } \\
\text { number of interrupts allowed, } \\
\text { requested output voltage } \\
\text { and output current interrupt } \\
\text { level. Information read } \\
\text { includes number of inter- } \\
\text { rupts occurred and the total } \\
\text { pulse on time. Other func- } \\
\text { tions include output regula- } \\
\text { tion, termination of pulse due } \\
\text { to faults and unauthorized } \\
\text { (run on) pulse detection. }\end{array}$ & FD \\
\hline WFC & $\begin{array}{l}\text { Waveform Capture. Four } \\
\text { channels capable of storing } \\
4 \mathrm{~K} \text { of } 13 \text { bit words at a } \\
3 \mathrm{MHz} \text { bit clock rate. }\end{array}$ & FD \\
\hline$A D C$ & $\begin{array}{l}\text { Analog to Digital Converter. } \\
32 \text { differential analog inputs. }\end{array}$ & GL and FD \\
\hline
\end{tabular}




\subsection{Vsystem:}

At the heart of the ECH_PS control is Vsystem, the control software. This powerful package has removed the need for the long, expensive and risky development of an in-house system. Vsystem combines an extensive yet easy-to-use graphics package with a networked, lexible, open real-time database. The six core components of Vsystem are described below.

3.1.1. Vaccess: Vaccess supports the individual components comprising Vsystem. It is the real-time database and library of access routines. The ECH_PS database was defined without programming, using ASCII text files generated with a text editor. This text file uses a keyword syntax and contains nested "include" files and the macro definitions for the CAMAC hardware. Currently, the ECH_PS database contains about 300 data channels. Channel information stored in the database includes:

Channel name

Current channel value

Conversion routines and constants

Change tolerance

Hardware type and address

Text information fields

Format and units used when reporting channel values

Alarm and warning limits

Since the various ECH_PS hardware require different channel types, three of eight data types supported by Vsystem are used:

Binary - a two-state channel

Integer - a channel holding 32-bit integer values, single value or array

Real - a single-precision floating point number, single value or array

Excerpts from the ECH_PS database text file are shown here.

\section{Hardware Macro Definitions}

define glcrate

define fdcrate

define GL_interlock_la

$$
\begin{gathered}
\text { "iotype CAMAC crate 1" } \\
\text { "iotype CAMAC crate 2" } \\
\text { "hm SE612A branch 1 } \\
\text { glcrate slot 22" } \\
\text { "hm L2284A branch } 1 \\
\text { fdcrate slot 22" }
\end{gathered}
$$

\begin{tabular}{|c|c|c|}
\hline \multicolumn{2}{|c|}{$\begin{array}{l}\text { \$Cooling_Water_Temp } \\
\text { in } \\
\text { binary } \\
\text { GL_interlock_la } \\
\text { subaddress } 5\end{array}$} & \multirow[t]{2}{*}{$\begin{array}{l}\text { Shivolt:state } \\
\text { in } \\
\text { soft } \\
\text { integer } \\
\text { label "High voltage state" }\end{array}$} \\
\hline $\begin{array}{l}\text { b0 } \\
\text { b1 } \\
\text { bvalue }\end{array}$ & $\begin{array}{l}\text { "NOT_OK" } \\
\text { "OK" } \\
\text { "NOT_OK" }\end{array}$ & \\
\hline \multicolumn{3}{|c|}{$\begin{array}{l}\text { \$AC_Voltage } \\
\text { in } \\
\text { real } 10 \\
\text { GL_adc } \\
\text { subaddress } 1 \\
\text { GL_adc_scale }\end{array}$} \\
\hline $\begin{array}{l}\text { label } \\
\text { slope } \\
\text { intercept } \\
\text { units } \\
\text { delta }\end{array}$ & $\begin{array}{l}\text { "Step regula } \\
4.5 \\
-4.5 \\
\mathrm{kVac} \\
0.1\end{array}$ & voltage" \\
\hline
\end{tabular}

\section{Channel Definitions}

Vgen, the database generating utility, reads the text file and creates a real-time database image. Although no programming is required to use Vsystem, a library of access routines is provided for the development of the custom/specific applications, in any high level language, to access the database. The ECH_PS employs Fortran for its specific application processes.

3.1.2. Vscan: Vscan provides the acsive connection between the input hardware and the Vsystem real-time database. Vscan scans the hardware at a rate specified by the user, and places the new values into the database.

3.1.3. Vdraw: Vdraw contains a complete set of drawing, editing and windowing tools. With the aid of the $v d$ raw tool box, control windows and tools are created. The ECH_PS control screen contains control windows with interactive objects called control tools. The control tools dynamically connect to the database and allow monitoring and control of the ECH.PS equipment. As the real-time database is being updated by the system, an active control window will reflect channel changes. By clicking a mouse button, holding a button and sliding the mouse, or entering values from the keyboard, channel values can be changed. Control tools are defined by a dialog box requesting all the information necessary in order to link a control tool to a particular database channel. Figure 2 shows the ECH_PS Main control window with some standard, as well as user created, control tools.

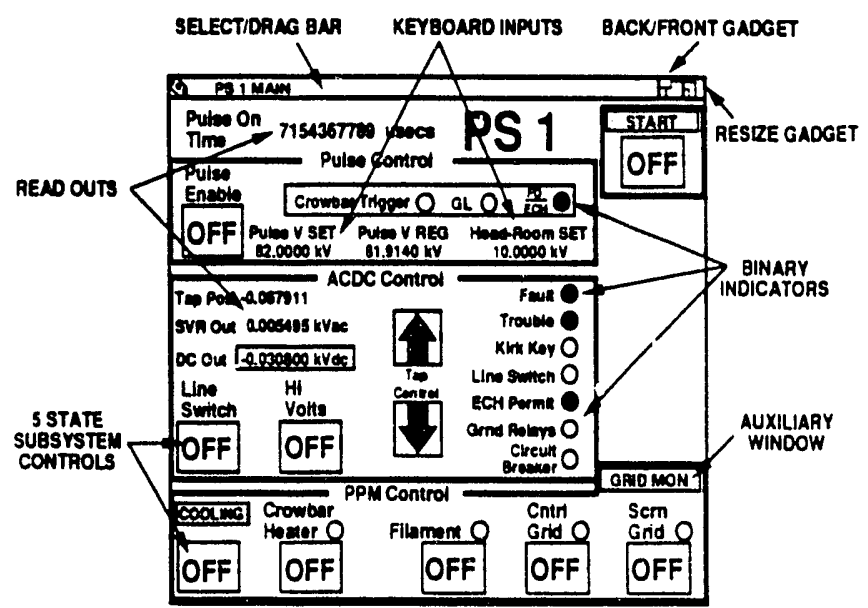

FIG. 2. The ECH_PS main control window.

The hierarchy chart in Fig. 3 shows the ECH_PS control window relationships. The state and main control windows are always present. The other control windows are brought up on operator request by the application of control buttons lcicated on the state and main control windows.

Although a standard symbols library is present, custom control tool symbols were created using the Vdraw symbolbuilder utility to illustrate the state of an ECH_PS channel. Figure 4 shows the five states of the control button created for each of the ECH.PS subsystems. A number of libraries of custom symbols were created for the ECH_PS system, and can be used in other control screens and windows.

3.1.4. Valarm: Valarm monitors channel alarms and exceptions. Valarm can signal the operators uudibly and visually when a channel enters warning or alarm states. Alarms can also be logged to disk files and spoken via DECtalk. 


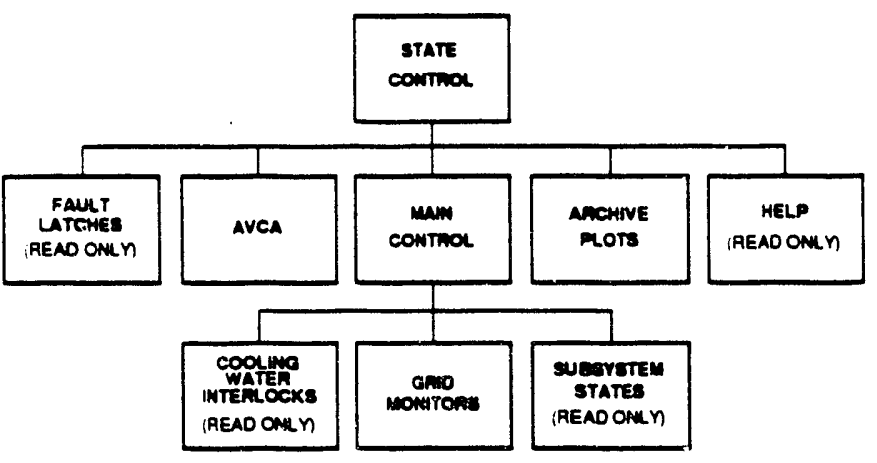

FIG. 3. The ECH_PS control window hierarchy.

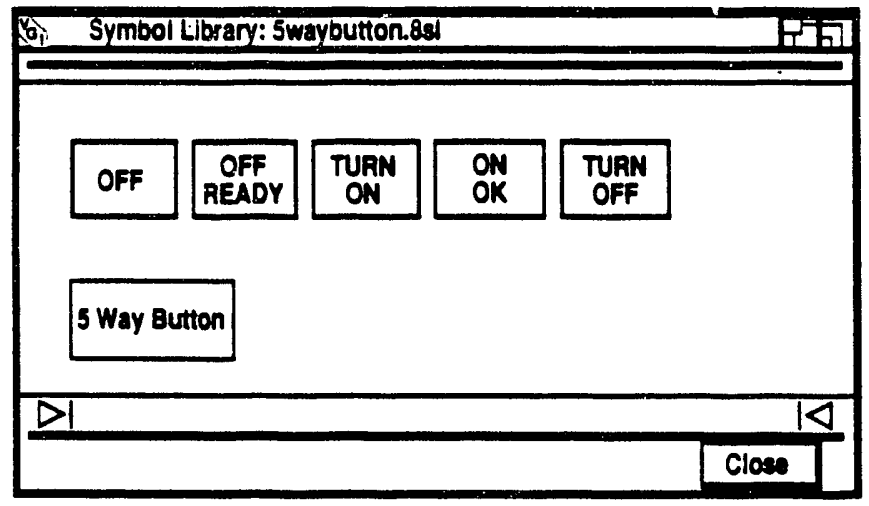

FIG. 4. ECH_PS five-state button.

3.1.5. Vlogger: Vlogger acquires data from the Vsystem database and logs it to standard output devices, including disk files. Vlogger will also play a logged file back into a real-time database.

3.1.6. Vscript: Vscript is an environment in which nonprogrammers can use scripting facilities to interact with the realtime database.

\subsection{ECH_PS Specific Application Processes}

Eight different processes were written specifically for the ECH.PS control system and its hardware. The source codes are in Fortran, and part of the codes are still under development for improvement or changes. These processes are automatically started up by a command file, along with the CAMAC driver process, at the beginning of ECH_PS operation. Some run continuously at a given rate. Others stand by and are awaken by other processes or changes in the database by the use of VMS Asynchronous System Traps (ASTs) [5]. Upon shutdown of the system, these processes and the CAMAC driver are stopped in an orderly fashion. Following is a description of these ECH_PS specific processes.

3.2.1 State mon: This is the program that controls and monitors operator turn on/off sequencing of the nine ECH.PS subsystems (Fig. 1). It does some of the system interlock checking, and implements simple sequencing where it can be carried out by the computer and its CAMAC hardware. Each power supply subsystem has two corresponding database channels associated with it. One is a logical channel to contain the state of the subsystem, and the second is a control channel to request a state change/transition. State transitions for each subsystem are handled by an AST booked to the control and state channels for that subsystem. The different states for each subsystem are OFF, OFF_READY, TURN_ON, ON_OK and TURN_OFF. The control tool that represents these five states is the five-state button on the Main control window (Figs. 2 and 4).

State mon also writes pulse information out to the AVCA module when proper sequencing has been performed. It also calculates the correct tap position for obtaining the correct input de voltage, and controls the tap changer raise and lower commands.

3.2.2. IImon: Ilmon monitors the status of the interlocks for the ECH_PS. It builds a list of the channels and device locations from the database to each interlock module in the system. The three interlock modules are read once every $1 \mathrm{msec}$ by Ilmon. The 16-1 bit inputs and 8-1 bit outputs of each module are read. Ilmon will read channels for more than one database.

3.2.3. Bindacode: Bindecode decodes the interlock data read by llmon to binary channels. It sorts through the database for all of the channels associated with the interlock modules. It wakes up on changes in the raw data and writes the changes to the database into the proper binary channel.

3.2.4. Fastmon: Fastmon sets up and handles monitoring of all of the analog channels in the database, and monitors the AVCA "number of interrupts" and "pulse on time." It is implemented to scan the ADC and AVCA modules at a $50 \mathrm{~Hz}$ rate. However, to ensure that Fastmon does not interfere unduly with the whole system, the waiting time between scans is user selectable (i.e., stored in a database channel). Control of this task is through a database channel which allows it to be stopped and started by the user. Presently, the wait time between scans is 250 msec. Fastmon also checks the serial highway for floating deck CAMAC communications.

3.2.5. Limit_check: This process does the limit checking for the analog channels and calculates the proper limits. It awakens into action when there is a change in value of any one of the analog channels in the database. It monitors the ac and $\mathrm{dc}$ voltages and sets the appropriate binary channels if a limit is exceeded. This program can only be connected to one database at a time.

3.2.6. Faults: Faults watches for state changes in the subsystem permissives and sets the system to the appropriate states. It sets the system to the correct state on a fault occurrence. An AST is booked to each permissive interlock and when that state goes bad, the appropriate control channels are set to the lowest allowable state (i.e., OFF). Faults only handles jumps to lower states. All sequencing to higher states is under operator and state_mon control.

3.2.7. AVCA: This program interfaces between the operator and the AVCA module. It handles all input from the AVCA. Output is handled within state_mon. This program is restricted to running only one database.

3.2.8. WFC: The WFC program handles all interactions between the operator and the waveform capture modules. It runs and intercepts requests for data from the waveform capture modules. The data is stored as arrays in ring buffers in the database based on the shot number. This program is restricted to running only one database. Currently the number of shots in the ring buffer is limited to ten. 


\subsection{Priorities}

Interlock/fault indication and response in subsequent state changes are of major importance to the operation of the power supply. Therefore, IImon and Bindecode have been given top priority to CPU time relative to the other ECH_PS specific application processes. State_mon with Faults, Limit_check, AVCA, and Fastmon with WFC follow in relative decreasing order or priority.

\subsection{CAMAC Hardware Driver Code}

The ECH_PS serial highway driver is driven by a code which is contained within Vsystem. Vsystem is capable of using a variety of CAMAC drivers as well as other non-CAMAC hardware.

\section{Start-up}

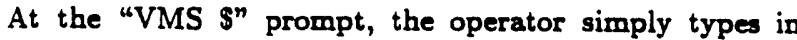
STARTPS1 to start the ECH_PS software. From the corresponding command file the following steps are performed.

(1) The database is opened and connected to.

(2) CAMAC communications are started up.

(3) The eight ECH_PS specific applications are started.

(4) Vdraw draws the State control window from which the other control windows are brought up.

(5) Operation continues with mouse and keyboard input.

\section{Continuing Developrivent}

Further development for improved performance continues in two areas: software upgrades of Vsystem from Vista Control Systems and changes in the ECH_PS specific application codes. The upgrades to Vsystem include faster response and more features for improved monitoring and control. The ECH_PS specific application processes are studied and modified as operation continues for faster response and simplicity in control.

With the addition of more high voltage power supplies for operation of more ECH gyrotrons, a number of challenges involving both computer software and hardware will be addressed. Some of the major concerns for controlling multiple supplies with the one computer control system are discussed below.

(1) Increased number of CAMAC crates and modules: one solution to minimize highway congestion is to convert to a one CAMAC crate operation per supply by relocating the floating deck modules to the ground level.

(2) Design and layout of multiple databases, specific application processes and control windows: Vsystem and the ECH_PS specific processes were designed with operation of multiple systems in mind. Most of the work will be in duplication, renaming and defining of the present database, processes and control windows to create additional control systems.

(3) MicroVax CPU: The present MicroVax II/GPX will have to be upgraded to the Vax 4000-series to handle the increased work load.

The number of additional systems that the one computer can handle is not clear at this time. By projection of the present CPU busy time, upgrading the CPU and converting to a one CAMAC crate per supply configuration, three supplies controlled by one computer with Vsystem is not unreasonable. One more supply is planned to be added at the end of this year, as is the CPU upgrade, and how efficiently the system can really perform should become more evident.

\section{Acknowledgments}

The ECH.PS layout and software specifications for the DIII-D application were written by G. Santamaria of General Atomics; B. Westervelt of Vista Control Systems programmed the ECH_PS specific application software.

This is a report of work sponsored by the U.S. Department of Energy under Contract No. DE-AC03-89ER51114.

\section{References}

[1] R.D. Eckard, H.W. Van Ness, and H. Stern, The Sustaining Neutral Beam Power Supply for the Mirror Fusion Test Facility, in Proceedings of the 8th Symposium on Engineering Problems of Fusion Research (November 1979).

[2] Digital Equipment Corp., VMS Installation and Operations: VAXstation I, II, II/GPX and MicroVax $I$ and $I I$ (1988) pp. 2-1 to 2-26.

[3] Vista Control Systems Inc., Vsystem Users Guide/Programmer's Guide (1990) Version 2.1.

[4] Digital Equipment Corp., VMS DECwindows Users Guide (1989), Version 5.3.

[5] Digital Equipment Corp., VMS Programming Guide to Creating Modular Procedures (1989) Version 5.3, Vol. 1 , pp. 3-19. 

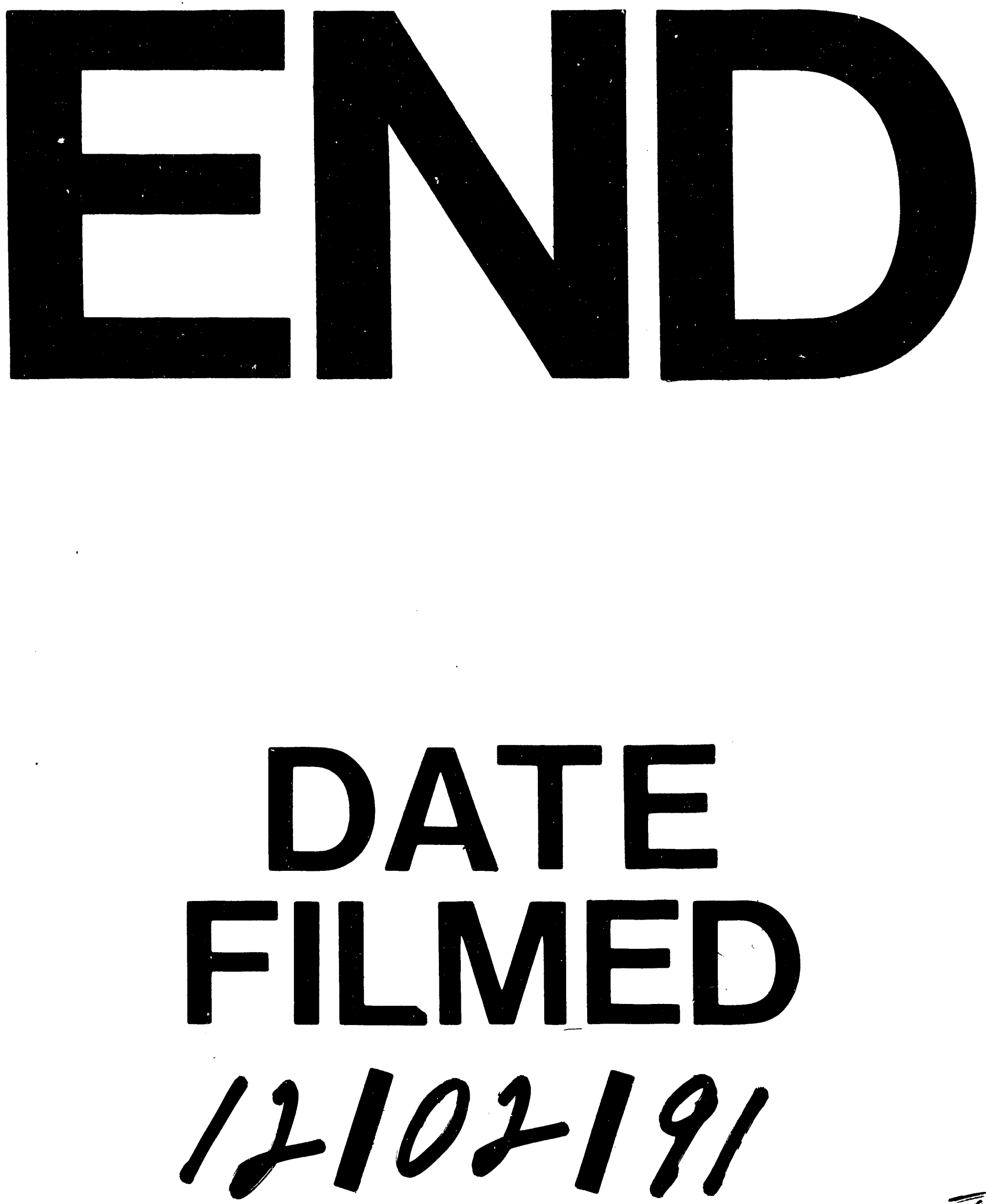
